\title{
Balkanologie
}

Balkanologie Revue d'études pluridisciplinaires

Vol. VIII, $n^{\circ} 1$ | 2004

Volume VIII Numéro 1

\section{Winnifrith (Tom J.), Badlands - Borderlands.A History of Southern Albania / Northern Epirus}

London : Duckworth, 2002, 219 p.

\section{Gilles de Rapper}

\section{(2) OpenEdition}

\section{Journals}

Édition électronique

URL : http://journals.openedition.org/balkanologie/2080

DOI : 10.4000/balkanologie.2080

ISSN : 1965-0582

\section{Éditeur}

Association française d'études sur les Balkans (Afebalk)

Édition imprimée

Date de publication : 1 juin 2004

ISSN : 1279-7952

\section{Référence électronique}

Gilles de Rapper, «Winnifrith (Tom J.), Badlands - Borderlands.A History of Southern Albania / Northern

Epirus », Balkanologie [En ligne], Vol. VIII, n 1 | 2004, mis en ligne le 21 janvier 2010, consulté le 17 décembre 2020. URL : http://journals.openedition.org/balkanologie/2080 ; DOI : https://doi.org/ 10.4000/balkanologie.2080

Ce document a été généré automatiquement le 17 décembre 2020.

(C) Tous droits réservés 


\title{
Winnifrith (Tom J.), Badlands - Borderlands.A History of Southern Albania / Northern Epirus
}

London : Duckworth, 2002, 219 p.

\author{
Gilles de Rapper
}

\section{RÉFÉRENCE}

Winnifrith (Tom J.), Badlands - Borderlands. A History of Southern Albania / Northern Epirus, London : Duckworth, 2002, $219 \mathrm{p}$.

1 Ce livre est le résultat d'une série d'enquêtes menées en Albanie et en Grèce en 1999 et fait suite à un certain nombre de publications du même auteur sur l'Albanie, et en particulier sur les Valaques d'Albanie du Sud. L'ambiguité du projet apparaît dans le titre, qui hésite entre "Albanie du Sud » et «Épire du Nord». Peut-on faire l'histoire d'une région qui n'a jamais constitué une unité politique ou administrative et dont la désignation même prête à discussion? On peut aussi s'interroger sur l'intérêt de retracer une histoire aussi longue (de 1200 avant J.C. à 2000 après) en seulement 120 pages (le reste du livre consiste en notes bibliographiques et en annexes portant sur la localisation de quelques lieux antiques), mais l'auteur annonce que son livre vise un public plus large que celui des seuls spécialistes.

2 En fait, ce qui intéresse Tom Winnifrith est la caractérisation de cette région, tout au long de son histoire, comme une région frontière, un borderland. C'est d'abord de frontière ethnique qu'il s'agit, plus que de frontière politique, car la région n'a cessé d'abriter des groupes s'opposant sur la base de la langue, de l'origine ou de la coutume commune : les Grecs de l'antiquité et leurs voisins épirotes et illyriens, les Byzantins et les Slaves, les Albanais et les Valaques et ainsi de suite. Le propos de l'auteur est de montrer l'extrême fluidité de ces frontières ethniques, qui s'accompagne des incessantes fluctuations des frontières politiques, rendant selon lui impossible, ou 
inadéquate, toute cartographie historique en ce qu'elle fige artificiellement les limites mouvantes et perméables d'entités politiques qui ne partagent pas la conception du territoire des États-nations modernes.

3 Le plan de l'ouvrage est chronologique. Après une introduction visant à planter le décor et à définir la région considérée (bizarrement limitée au nord par le fleuve Shkumbin et au sud par l'actuelle frontière gréco-albanaise, ce qui semble donner à cette frontière récente une importance plurimillénaire), sept chapitres découpent l'histoire en autant de grandes périodes : la Grèce jusqu'en 400 avant J.C., la Macédoine et Rome (400 av. J.C. - 400 ap. J.C.), Byzance (400-1200), « l'anarchie » (1200-1500), les Ottomans (1500-1800), les Grandes puissances (1800-1912) et "l'indépendance» (1912-2000).

4 Les sources sont variées mais, en dehors des auteurs antiques et des voyageurs occidentaux du XIX ${ }^{\mathrm{e}}$ siècle, dont l'auteur est familier, elles consistent le plus souvent en synthèses occidentales, ou traduites en langues occidentales. À l'exception des carnets de l'Anglais S.S. Clarke (1897-1924), qui parcourt la région juste après la première guerre mondiale, Winnifrith n'utilise que des matériaux bien connus par ailleurs. L'auteur s'est lui-même promené dans la région, mais on peut douter de certaines de ces observations, en raison à la fois de la méconnaissance des langues locales et, comme il le reconnaît lui-même, d'un penchant à voir des Valaques partout (p. 27). Un certain nombre de toponymes et de mots étrangers souffrent pour cette même raison d'une transcription erronée (Pogradeç pour Pogradec, Seleniçë pour Selenicë) ou bizarre (p. 104, devirshime pour devshirme).

5 Dans l'ensemble, le contenu peut être réparti en trois catégories: la première rassemble les passages consacrés à la discussion des sources et à leur évaluation, ce qui donne quelques développements intéressants, comme à propos des récits de voyages du $\mathrm{XIX}^{\mathrm{e}}$ siècle, ou encore à propos des enjeux politiques contemporains des débats scientifiques sur l'unité politique des Illyriens ou sur l'appartenance ethnique des Épirotes. On trouve dans la deuxième catégorie des exposés sur l'histoire politique, militaire et dynastique telle qu'elle s'est déroulée dans la région. C'est sans doute la catégorie la moins intéressante, même si l'auteur n'est pas mauvais conteur, car elle apporte en fin de compte peu de choses sur l'histoire de la région (elle est plutôt l'histoire dans la région), rien en tout cas que l'on ne trouve déjà par exemple dans les ouvrages de synthèse sur l'histoire des empires byzantin et ottoman. On trouve enfin dans la troisième catégorie des spéculations sur l'histoire de la frontière ethnique entre les Grecs et leurs voisins du nord-ouest. On retiendra par exemple l'hypothèse d'un " afflux » albanais depuis l'Albanie du Nord vers l'Albanie du Sud au XIV ${ }^{e}$ siècle, dans une région jusqu'alors occupée par des Slaves et par quelques îlots grecs ayant survécu aux invasions slaves, ou encore celle d'une avancée de l'hellénisme entre les XVI ${ }^{\mathrm{e}}$ et $\mathrm{XIX}^{\mathrm{e}}$ siècles. Si l'auteur est soucieux de "dénationaliser » la vision de l'histoire, au rebours des histoires nationales grecque et albanaise qu'il renvoie souvent dos-à-dos, la plupart de ses hypothèses restent des spéculations qu'il est difficile d'infirmer ou de confirmer à partir des matériaux présentés ici.

Malgré les limites liées à la nature même du projet (faire l'histoire d'une région méconnue à l'usage du general reader), le livre retient l'attention par son regard critique sur l'histoire officielle ainsi que par son souci de rendre la complexité du peuplement de la région en dépassant les catégories nationales à travers lesquelles on le considère 
le plus souvent. Il tient en ce sens ses objectifs, même si le spécialiste reste un peu sur sa faim. 